\title{
ANALISIS KINERJA JARINGAN SENSOR NIRKABEL UNTUK EDGE COMPUTING MENGGUNAKAN LORA SX1278
}

\author{
Mochammad Hannats Hanafi Ichsan *1 \\ ${ }^{1}$ Teknik Komputer, Fakultas Ilmu Komputer, Universitas Brawijaya Malang \\ Email: ${ }^{1}$ hanas.hanafi@ub.ac.id \\ *Penulis Korespondensi
}

(Naskah masuk: 10 Juni 2020, diterima untuk diterbitkan: 15 Oktober 2021)

\begin{abstract}
Abstrak
Jaringan Sensor Nirkabel (WSN) adalah salah satu teknologi yang muncul untuk proses deploy dari Internet of Things, Smart System, Machine to Machine networks dan lain sebagainya. Dimana setiap node dari WSN tersebut memiliki kemampuan untuk sensing, komputasi hinga proses pengiriman data. Pemrosesan data secara umum dilakukan pada Cloud atau node lain, hal ini menyebabkan beban kerja dari node lain atau Cloud tersebut menjadi cukup berat. Proses sensing dapat dilakukan dengan menggunakan berbagai sensor sesuai kebutuhan, sedangkan teknologi untuk pemrosesan pada node sensing disebut dengan teknologi Edge Computing. Konsep dari Edge Computing adalah bagaimana sebuah node bisa berpikir untuk menyelesaikan masalah atau mengambil keputusan. Kemudian data hasil pengolahan tersebut dikirimkan ke node yang lain untuk diolah lebih lanjut sehingga kinerja dari node lain atau Cloud lebih ringan. Salah satu teknologi dalam pengiriman data yang dapat dipergunakan dengan baik dan kemampuan jarak komunikasinya cukup panjang adalah LoRa. Salah satu topologi untuk WSN yang dinilai sangat baik untuk pengiriman data adalah Mesh, dimana seluruh node dapat berkomunikasi dengan baik. Oleh karena itu pada penelitian ini akan difokuskan untuk melakukan analisis kemampuan LoRa dalam pengiriman data berdasarkan jarak dan besar data. Karena pada implementasinya jarak berdasarkan besar data hasil pengolahan dari Edge Computing cukup bervariasi. Sehingga pada penelitian ini menghasilkan studi kelayakan LoRa sebagai perangkat untuk proses komunikasi pada WSN menggunakan topologi Mesh. Berdasarkan hasil penelitian yang dilakukan secara keseluruhan LoRa cukup baik untuk pengiriman data hingga 256 bytes dan jarak 300 meter berdasarkan delay, throughput, RSSI dan SNR sehingga sangat layak untuk diimplementasikan pada Edge Computing.
\end{abstract}

Kata kunci: Wireless Sensor Network, Edge Computing, LoRa, Ukuran Data, Jarak Pengiriman.

\section{PERFORMANCE ANALYSIS OF WIRELESS SENSOR NETWORK FOR EDGE COMPUTING USING LORA SX1278}

\begin{abstract}
Wireless Sensor Networks (WSN) is one of the emerging technologies for the deployment of the Internet of Things, Smart Systems, Machine to Machine networks and so on. Where each node of the WSN has the ability to sensing, computation until the process of sending data. Data processing is generally done on the Cloud or other nodes, this causes the workload of other nodes or the Cloud to be quite heavy. The sensing process can be done by using various sensors as needed, while the technology for processing the sensing node is called Edge Computing technology. The concept of Edge Computing is how a node can think to solve a problem or make a decision. Then the processing data is sent to another node for further processing so that the performance of other nodes or the Cloud is lighter. One of the technologies in sending data that can be used properly and the ability of its long communication distance is LoRa. One of the topologies for WSN that is considered very good for sending data is Mesh, where all nodes can communicate well. Therefore this research will focus on analyzing the ability of LoRa in sending data based on distance and data size. Because in the implementation of the distance based on the large data processing results from Edge Computing is quite varied. So that this research resulted in a feasibility study of LoRa as a device for the communication process at WSN using Mesh topology. Based on the results of research conducted overall LoRa is good enough for sending data up to 256 bytes and a distance of 300 meters based on delay, throughput, RSSI and SNR so it is very feasible to be implemented on Edge Computing.
\end{abstract}

Keywords: Wireless Sensor Networks, Edge Computing, LoRa, Data Size, Range. 


\section{PENDAHULUAN}

Jaringan Sensor Nirkabel atau Wireless Sensor Network (WSN) adalah sebuah teknologi yang memiliki cakupan cukup luas untuk diteliti (Sabor, et al., 2017). Cakupan tersebut berdasarkan subyek (misalkan perangkat lunak atau perangkat keras) atau obyek (misalkan area pertanian, perkantoran, rumah pintar, dan lain sebagainya) (Cao, et al., 2019). Implementasi dari WSN juga dapat dimanfaatkan dalam berbagai bentuk misalkan Internet of Things, Smart System, Machine to Machine networks dan lain sebagainya (Adiono, et al., 2015). Perangkat lunak misalkan, dari segi proses pengiriman data, topologi, konfigurasi, komputasi, lokalisasi, proses routing, low power consumption dll (Yan, et al., 2016) atau dari perangkat keras misalkan mikrokomputer yang dipergunakan (arduino uno, mega, RF, LoRa, Zigbee, 802.11 dll) serta dari segi sensor yang dipergunakan (sensor suhu, jarak, air dll) (Costa, 2020). Sehingga pengkajian WSN memerlukan detail dari subyek maupun obyek yang diteliti terkait kinerja dari perangkat WSN tersebut.

Pada WSN jumlah node seringkali lebih dari satu, sebuah node biasanya berisi sensor; komputasi; dan perangkat komunikasi (Sujana, 2018). Namun macam node yang dipergunakan ada dua yaitu sensor node (node untuk sensing; kadang disebut juga end node) dan master node (untuk pengumpulan data untuk diolah atau dikirimkan ke tempat lain; terkadang disebut juga host node) (Fauzi, et al., 2018). Seringkali, pengolahan data hasil sensor dilakukan pada master node, sehingga proses komputasi pada master node cukup padat. Master node harus membagi waktu untuk menerima data dari end node, kemudian mengolah komputasinya dan mengirimkan ke tempat lain (server cloud misalkan) (Ichsan, et al., 2019). Beberapa kriteria WSN adalah memiliki kapasitas yang terbatas baik dari segi sumber daya, kemampuan proses maupun usia (Astuti \& Wibisono, 2017).

Salah satu teknologi yang sedang berkembang adalah Edge Computing, dimana konsep dari Edge Computing adalah komputasi terpisah pada end node (Y., et al., t.thn.). Sehingga data yang dihasilkan oleh sensor diolah terlebih dahulu menggunakan beberapa algoritma pengambilan keputusan, kemudian setelah itu hasil pengolahan data dikirimkan ke master node. Pengolahan data pada edge computing, dapat dilakukan menggunakan berbagai algoritma, misalkan: Logika Fuzzy; Algoritma Genetika; Naive Bayes; Big Data; (Ichsan, et al., 2019) atau algoritma cerdas lain dimana keputusan hasil algoritma hanya untuk node tersebut (Zhou, et al., 2019). Jika algoritma yang dilakukan membutuhkan masukan dari node lain, atau algoritma saling mendukung untuk sebuah keputusan bersama tetap dapat dilakukan dengan konsep Edge Computing. Konsep Edge Computing ini memiliki tujuan untuk meminimalisir kinerja berlebihan dari sebuah node, sehingga beban kerja dibagi pada node lain.

Untuk menunjang Jaringan Sensor Nirkabel dengan banyaknya node yang memungkinkan untuk diimplementasikan, beberapa parameter dapat dipergunakan antara lain seperti Low Cost (Teixeira, et al., 2019) dan Low Power (Chao, et al., 2018). Sehingga untuk mendukung proses prototyping dan parameter low cost serta low power perangkat mikrokomputer yang dipergunakan adalah Arduino Nano. Untuk perangkat komunikasi yang sangat mendukung parameter tersebut adalah LoRa SX1278. LoRa adalah perangkat jaringan nirkabel yang menggunakan frekuensi radio, sehingga jarak yang dapat ditempuh relatif lebih jauh (Boterovalencia, et al., 2019). LoRa memiliki kemampuan untuk komunikasi dalam jarak yang relatif jauh dengan membutuhkan konsumsi daya yang rendah (Bhawiyuga \& Yahya, 2018).

Topologi yang paling sesuai untuk WSN adalah Mesh, dimana setiap node akan saling terhubung (Adiono, et al., 2015). Jika salah satu node tidak terkoneksi dengan baik, sesuai konsep dari topologi ini maka node tersebut akan menggunakan node lain untuk saling berkomunikasi. Sehingga kemungkinan data diterima oleh master node akan lebih besar. Meskipun proses komunikasi LoRa dapat dikatakan searah, namun bisa di set untuk proses komunikasi dua arah secara bergantian (Raharjo, et al., 2019). Jarak dan besar data dipergunakan untuk menghitung Delay, RSSI, Throughput dan SNR (Silva, et al., 2017).

Sehingga pada penelitian ini didapatkan kesesuaian untuk pemanfaatan Arduino dan LoRa untuk diimplementasikan pada WSN dengan konsep Edge Computing. Dimana end node memproses Edge Computing dengan membuat data dan memprosesnya, kemudian data tersebut dikirimkan ke master node berdasarkan jarak dan besar data.

\section{METODE PENELITIAN}

Penelitian ini dilakukan untuk fokus pada analisis kinerja Lora untuk Implementasi dari Edge Computing. Sehingga perangkat yang diimplementasikan hanya sensor node / end node sebagai perangkat Edge Computing dan master node. Berdasarkan Gambar 1, sebuah sensor node adalah perangkat untuk mendapatkan data dari lingkungan yang diamati. Namun pada penelitian ini tidak fokus terhadap sensor, sehingga data yang diolah adalah didapatkan dari random proses yang diolah oleh arduino. Kemudian data dari arduino diproses oleh Lora untuk dikirimkan ke master node.

Pada end node, memiliki kebutuhan untuk mengolah data dan bekerja sendiri tanpa master node untuk mengolah data. End node dapat mengolah algoritma cerdas misalkan Logika Fuzzy, Jaringan Syaraf Tiruan, Algoritma Bayes, Sorting, Random Data dan lain sebagainya. Konsep Edge Computing 
adalah komputasi pada end node, bukan pada master node. Seringkali pemrosesan pada master node, sehingga jika master node melakukan pemrosesan dari banyak node, maka beban dari master node sangat besar.

Edge Computing / Sensor Node

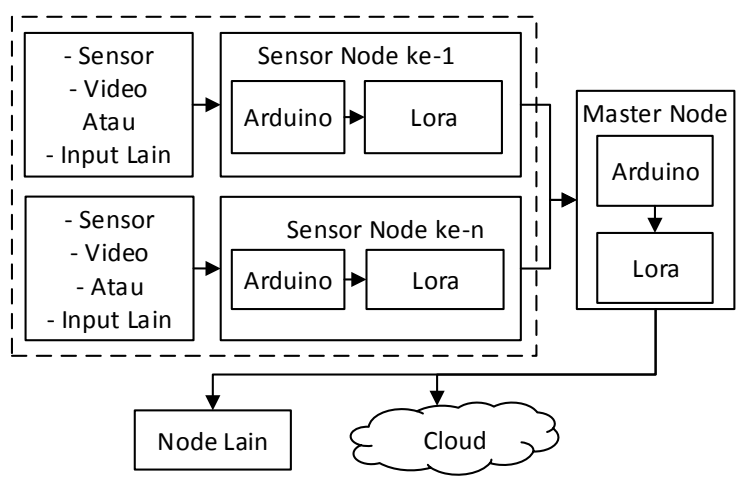

Gambar 1. Desain Metode Penelitian

Pada penelitian ini, besar data yang dilakukan adalah menggunakan Random Data. Data yang diacak untuk dikirimkan sebesar 1 hingga 256 bytes. Untuk jarak komunikasi dilakukan mulai 10 hingga 300 meter, karena sesuai datasheet kinerja Lora hingga 300 meter saja. Pada penelitian sebelumnya yang dilakukan melakukan analisis Lora pada perangkat simulator, tidak pada perangkat asli yang diimplementasikan pada perangkat keras (Aroeboesman, et al., 2018). Sehingga pada akhir penelitian ini didapatkan kesesuaian analisis terhadap lingkungan nyata jika diimplementasikan.

Untuk mengetahui tingkat kehandalan dari sebuah sistem, diperlukan pengujian. Untuk melakukan pengujian kehandalan sistem ini, diperlukan untuk mengukur berdasarkan jarak dan besar data terhadap kinerja dari node yang dimiliki. Parameter untuk komunikasi Jaringan Sensor Nirkabel (WSN) yang paling sesuai adalah Delay, RSSI, Throughput dan SNR (Silva, et al., 2017). Delay dipergunakan untuk mengukur seberapa lama waktu yang dibutuhkan untuk mengirimkan data. RSSI (Received Signal Strength Indicator) untuk mengukur indikator kekuatan sinyal. Throughput dipergunakan untuk mengukur bandwidth aktual dan SNR (Signal to Noise rasio) untuk menentukan kualitas sebuah sinyal. Parameter ini adalah parameter minimal untuk mengukur kehandalan sebuah jaringan sensor nirkabel.

\section{PERANCANGAN SISTEM}

Pada bagian ini akan dijelaskan terkait perancangan sistem yang dilakukan. Perancangan dilakukan menjadi empat bagian antara lain perancangan perangkat keras, perancangan perangkat lunak, perancangan topologi dan perancangan pengujian. Hal ini perlu dilakukan agar proses penelitian lebih sistematis dan terarah.

\subsection{Perancangan Perangkat Keras}

Perancangan ini dilakukan untuk merancang perangkat keras yang dipergunakan baik dipergunakan sebagai master node atau end node. Tiap node menggunakan mikrokomputer arduino nano dan LoRa SX1278.

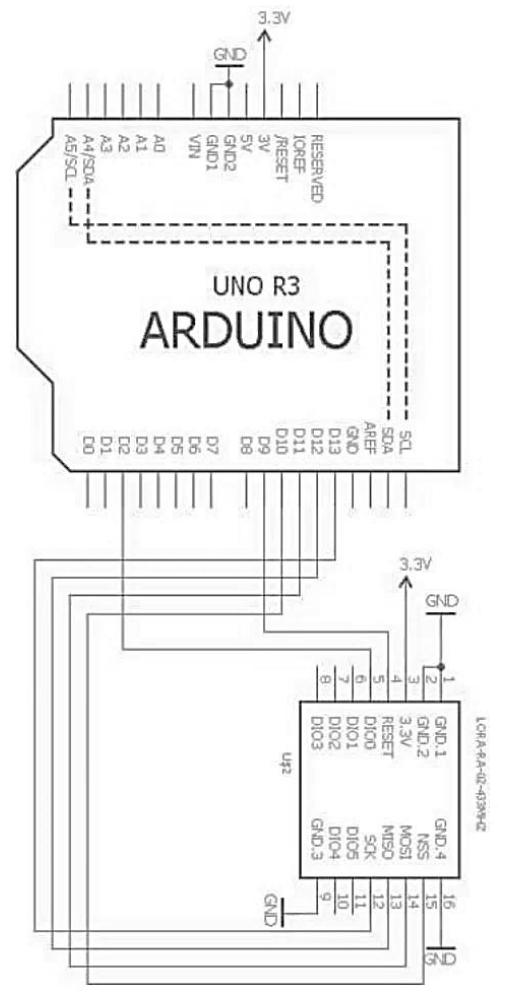

Gambar 2. Skematik Diagram Rangkaian Seluruh Node

Pada Gambar 2. tersebut rangkaian secara keseluruhan hubungan kaki Pin dari perangkat kerasnya dapat dilihat pada Tabel 1 . berikut. Tidak seluruh kaki perangkat keras dipergunakan. Hanya yang diperlukan saja yang dihubungkan antara arduino uno dengan LoRa.

Tabel 1. Rangkaian Perangkat Keras

\begin{tabular}{ccc}
\hline Perangkat & Arduino Nano & LoRa \\
\hline \multirow{6}{*}{ Pin } & VCC & VCC (3) \\
& GND & GND (9) \\
& SCK (13) & SCK (12) \\
& MISO (12) & MISO (13) \\
& MOSI (11) & MOSI (14) \\
& PIN 08 & RESET (4) \\
& PIN A2 & NSS (14) \\
\hline
\end{tabular}

\subsection{Perancangan Perangkat Lunak}

Pada perancangan perangkat lunak ini akan dilakukan perancangan terkait bagaimana jalannya dari sistem untuk dapat diimplementasikan sehingga dapat dilakukan analisis. Seperti pada Gambar 3, Node Pengirim adalah End node yang melakukan inisialisasi data. End node bertindak sebagai Edge Computing yang melakukan sensing hingga pengolahan data. Data berbentuk string dan waktu dengan panjang data yang bervariasi. Kemudian dilakukan pengiriman data terhadap master node. Setelah master node menerima data, maka data 
waktu yang diterima oleh master node akan mengurangi waktu dimana master node menerima data. Sehingga dapat dilakukan perhitungan untuk delay antara master dan end node. Jika data tidak dapat dikirimkan, maka end node akan tetap berulang hingga data dapat dikirimkan. Proses ini akan terus berulang terus menerus sesuai kebutuhan untuk proses analisis kinerja.

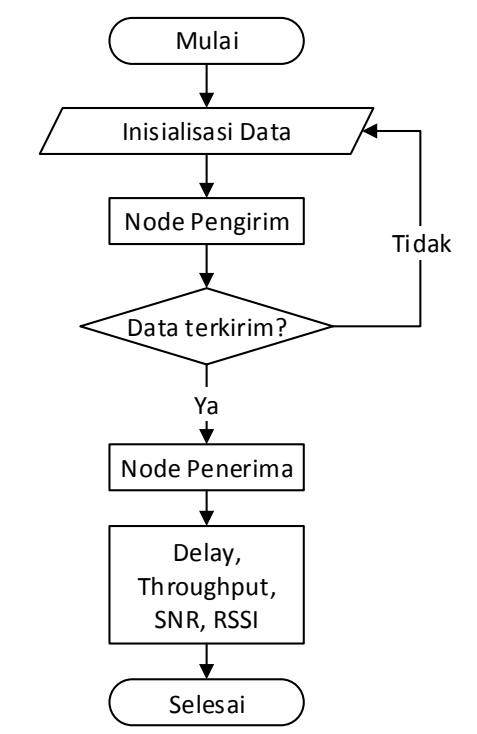

Gambar 3. Perancangan Perangkat Lunak

\subsection{Perancangan Topologi}

Topologi yang dipergunakan pada penelitian ini adalah topologi Mesh. Dimana tiap node dapat saling berkomunikasi. Pada Gambar 4. tersebut dapat dilihat jika masing-masing node bisa saling berkomunikasi, baik antar end node atau masingmasing end node dengan master node. Pada penelitian ini menggunakan 4 node. Satu node master dan 3 end node. Pada gambar tersebut master node diberi nama "Node Master" sedangkan end node diberi nama "node 1, node 2, dan node 3". End node ini adalah sensor node yang merepresentasikan Edge Computing.

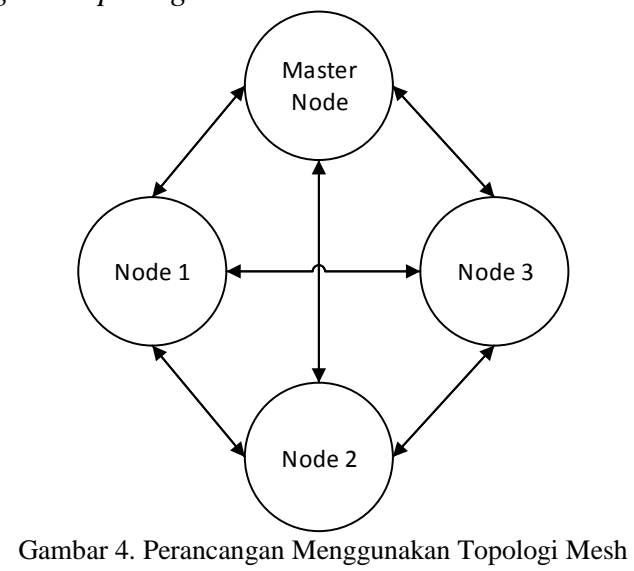

\subsection{Perancangan pengujian}

Berdasarkan perancangan topologi yang telah dilakukan akan dilakukan beberapa skema pengujian. Skema pengujian antara lain terhadap jarak dan besar data, kemudian dengan kombinasi tiap node yang dimiliki.

Untuk jarak maksimum dari LoRa SX1278 adalah 300 meter. Sehingga analisis pengujian akan dilakukan dengan menghitung mulai dari 10, 100, 200 dan 300 meter. Jarak tersebut akan dikombinasikan dengan besar data. Besar data ini asumsinya adalah data hasil pengolahan dari Edge Computing pada arduino nano. Besar data yang dipergunakan bervariasi mulai dari 1 bytes, 32, 64, 128 hingga 256 bytes. Kombinasi node yang dipergunakan untuk pengujian antara lain:

a. Node 2-Node 1-Master Node

b. Node 3 - Node 1-Master Node

c. Node 1 - Node 2-Master Node

d. Node 3 - Node 2-Master Node

e. Node 1 - Node 3-Master Node

f. Node 2-Node 3-Master Node

Pada pengujian tersebut Node 1, 2 dan 3 bertidak sebagai End Node dan Master Node sebagai penerima data paling akhir. Kode $\mathrm{a}, \mathrm{b}, \mathrm{c}, \mathrm{d}$, e dan $\mathrm{f}$ dipergunakan juga pada tabel tiap-tiap pengujian yang akan dibahas pada sub bab hasil dan pembahasan. Masing-masing kode nomor pengujian tersebut akan disajikan sebagai rata-rata yang dihasilkan dari 20 kali pengujian. Setiap 20 kali pengujian dilakukan karena cukup untuk merepresentasikan pengambilan data tiap node.

\section{HASIL DAN PEMBAHASAN}

Pada bagian ini akan dijelaskan terkait proses hasil pengujian yang dilakukan. Pengujian yang dilakukan antara lain menguji Delay, Throughput, RSSI dan SNR. Masing-masing parameter tersebut diuji terhadap jarak dan besar data. Dimana jarak dan besar data adalah parameter yang sangat berpengaruh terhadap pengiriman data. Masingmasing pengujian dilakukan dengan proses multihop dengan 3 node. Tiga node ini dipilih karena jika menggunakan 4 node (3 sebagai End Node dan 1 sebagai Master Node) adalah sebagai jarak terjauh yang bisa dilakukan dengan topologi Mesh.

Pengujian jarak masing-masing dilakukan dengan menggunakan beberapa variasi jarak sesuai datasheet jarak maksimal yang dimiliki oleh LoRa yaitu 300 meter. Sehingga ukuran variasi jarak yang dipergunakan adalah 10 meter, 100 meter, 200 meter dan 300 meter. Sedangkan pengujian besar data, dipilih berdasarkan variasi dari 1, 32, 64, 128 dan 256 byte. Data ini merupakan variasi dari representasi hasil komputasi dari pengolahan Edge Computing. Seluruh data pengujian yang disajikan pada sub bab ini adalah rata-rata hasil pengujian yang masing-masing dilakukan sebanyak 20 kali.

\subsection{Pengujian Delay}

Parameter pertama untuk menguji kehandalan dari sebuah sistem adalah end-to-end delay, dalam 
hal ini adalah antar node baik antar node 1 , node 2 , node 3 dan master node. Pada Tabel 2. Disajikan data terkait jarak terhadap besar data yang dihasilkan. Data yang disajikan dalam satuan milidetik / ms, kecuali data dengan format " $\operatorname{xxx}(\mathrm{d})$ " berarti data disajikan dalam format detik. Tabel 2 . Menunjukkan bahwa hingga seluruh pengujian, seluruh data berhasil dikirimkan dengan baik karena dapat dikirimkan dibawah 1 detik. Namun pada pengujian terakhir pada jarak 300 meter dengan besar data 256 bytes data dapat dikirimkan dalam waktu 31 detik, hal ini mungkin dapat dikatakan hasil kurang baik.

Tabel 2. Hasil Pengujian Delay ke-1

\begin{tabular}{|c|c|c|c|c|c|c|}
\hline $\begin{array}{c}\text { No } \\
\text { • }\end{array}$ & 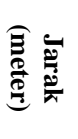 & 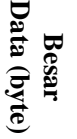 & $\begin{array}{l}\text { Min } \\
\text { "c" } \\
(\mathrm{ms})\end{array}$ & $\begin{array}{l}\text { Min } \\
\text { "d" } \\
(\mathrm{ms})\end{array}$ & $\begin{array}{l}\text { Max } \\
\text { "e" } \\
(\mathrm{ms})\end{array}$ & $\begin{array}{l}\text { Max } \\
\text { "f" } \\
(\mathbf{m s})\end{array}$ \\
\hline 1 & & 1 & 96 & 193 & 98 & 194 \\
\hline 2 & & 32 & 181 & 362 & 189 & 367 \\
\hline 3 & 10 & 64 & 261 & 520 & 277 & 530 \\
\hline 4 & & 128 & 425 & 851 & 433 & 870 \\
\hline 5 & & 256 & 746 & 1498 & 753 & 1507 \\
\hline 6 & & 1 & 96 & 193 & 97 & 194 \\
\hline 7 & & 32 & 180 & 363 & 181 & 363 \\
\hline 8 & $\begin{array}{l}10 \\
0\end{array}$ & 64 & 261 & 522 & 263 & 529 \\
\hline 9 & 0 & 128 & 430 & 861 & 437 & 862 \\
\hline 10 & & 256 & 749 & 1498 & 759 & 1503 \\
\hline 11 & & 1 & 96 & 192 & 96 & 193 \\
\hline 12 & & 32 & 176 & 350 & 178 & 355 \\
\hline 13 & $\begin{array}{c}20 \\
0\end{array}$ & 64 & 261 & 522 & 265 & 528 \\
\hline 14 & 0 & 128 & 430 & 861 & 453 & 868 \\
\hline 15 & & 256 & 749 & 1499 & 749 & 1507 \\
\hline 16 & & 1 & 96 & 193 & 96 & 193 \\
\hline 17 & & 32 & 176 & 352 & 183 & 359 \\
\hline 18 & 30 & 64 & 248 & 497 & 263 & 822 \\
\hline 19 & 0 & 128 & 410 & 820 & 430 & 861 \\
\hline 20 & & 256 & 1582(d) & $\begin{array}{c}31657(\mathrm{~d} \\
)\end{array}$ & $\begin{array}{c}1585(\mathrm{~d} \\
)\end{array}$ & $\begin{array}{c}3171(\mathrm{~d} \\
)\end{array}$ \\
\hline
\end{tabular}

Pada Tabel 3. adalah kelanjutan rekapitulasi hasil pengujian delay kelanjutan dari Tabel 2 yang hanya menyajikan delay minimum dan maksimum. Tabel 3. Menyajikan rata-rata pengiriman delay. Pada rata-rata tersebut, disebutkan bahwa pada pada jarak 300 meter dengan besar data 256 bytes memiliki rata-rata pengiriman data selama 3 detik dan dapat dikatakan relatif lama.

Tabel 3. Hasil Pengujian Delay ke-2

\begin{tabular}{ccccc}
\hline No. & $\begin{array}{c}\text { Jarak } \\
\text { (meter) }\end{array}$ & $\begin{array}{c}\text { Besar } \\
\text { Data } \\
\text { (byte) }\end{array}$ & $\begin{array}{c}\text { Avg } \\
\text { "a" }\end{array}$ & $\begin{array}{c}\text { Avg } \\
\text { "b" }\end{array}$ \\
\hline 1 & & 1 & 96 & 193 \\
2 & & 32 & 183 & 363 \\
3 & 10 & 64 & 266 & 523 \\
4 & & 128 & 427 & 855 \\
5 & & 256 & 749 & 1500 \\
6 & & 1 & 96 & 193 \\
7 & & 32 & 180 & 363 \\
8 & \multirow{2}{*}{100} & 64 & 261 & 524 \\
9 & & 128 & 433 & 861 \\
10 & & 256 & 751 & 1500 \\
11 & & 1 & 96 & 192 \\
12 & \multirow{2}{*}{200} & 32 & 176 & 352 \\
13 & & 64 & 262 & 524 \\
14 & & 128 & 435 & 863
\end{tabular}

\begin{tabular}{ccccc}
\hline No. & $\begin{array}{c}\text { Jarak } \\
\text { (meter) }\end{array}$ & $\begin{array}{c}\text { Besar } \\
\text { Data } \\
\text { (byte) }\end{array}$ & $\begin{array}{c}\text { Avg } \\
\text { "a" }\end{array}$ & $\begin{array}{c}\text { Avg } \\
\text { "b" }\end{array}$ \\
\hline 15 & & 256 & 749 & 1500 \\
16 & & 1 & 96 & 193 \\
17 & & 32 & 180 & 355 \\
18 & 300 & 64 & 255 & 658 \\
19 & & 128 & 420 & 842 \\
20 & & 256 & 6339895 & 3167725 \\
\hline
\end{tabular}

Selanjutnya dari tabel tersebut jika disajikan dalam bentuk grafik dapat dilihat pada Gambar 5 . Dimana disajikan untuk sumbu vertikal adalah delay dalam satuan detik dan sumbu horizontal adalah rata-rata pengujian.

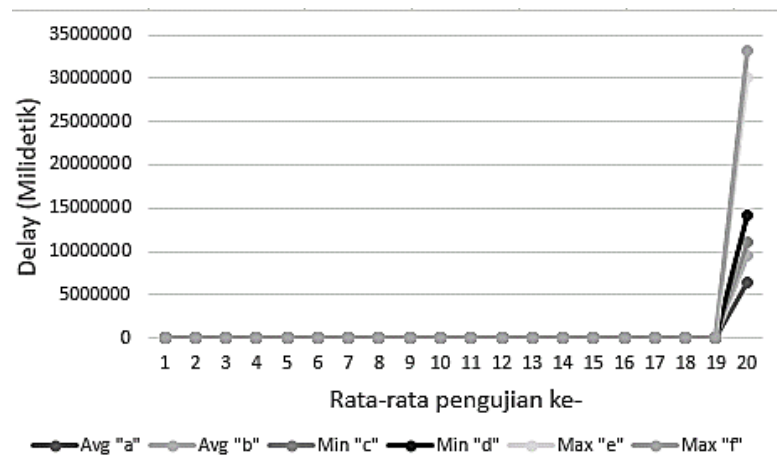

Gambar 5. Rekapitulasi Pengujian Delay

Pada Gambar 5. disajikan bahwa anomali pengujian dari jarak 10 hingga 300 meter dan besar data 1 hingga 256 bytes berhasil. Namun dari seluruh rata-rata pengujian nomor 1 hingga 19 dikatakan sangat baik karena masih dibawah 1 detik. Namun pada pengujian nomor 20 delay yang dihasilkan untuk pengiriman masing-masing node relatif tinggi. Sehingga tidak direkomendasikan untuk diimplementasikan pada jarak 300 meter dan besar data 256 bytes.

\subsection{Pengujian Throughput}

Skema pengujian ke-2 selanjutnya adalah pengujian throughput, pengujian ini dipergunakan untuk melakukan analisis bandwidth yang diperlukan untuk pengiriman data. Sehingga bandwidth aktual untuk melakukan pengiriman data dapat diberikan justifikasi secara obyektif. Tabel 4 . serta Tabel 5. menunjukkan bahwa jarak dan besar data terhadap throughput pada masing-masing skema sesuai perancangan pengujian.

Tabel 4. Hasil Pengujian Throughput ke-1

\begin{tabular}{ccccc}
\hline No. & $\begin{array}{c}\text { Jarak } \\
\text { (meter) }\end{array}$ & $\begin{array}{c}\text { Besar } \\
\text { Data (byte) }\end{array}$ & $\begin{array}{c}\text { Avg "a" } \\
\text { (kbps) }\end{array}$ & $\begin{array}{c}\text { Avg "b" } \\
\text { (kbps) }\end{array}$ \\
\hline 1 & & 1 & 0,01 & 0,01 \\
2 & & 32 & 0,01 & 0,01 \\
3 & \multirow{2}{*}{10} & 64 & 0,01 & 0,01 \\
4 & & 128 & 0,01 & 0,01 \\
5 & & 256 & 0,01 & 0,01 \\
6 & & 1 & 0,06 & 0,03 \\
7 & & 32 & 0,06 & 0,08 \\
8 & \multirow{2}{*}{100} & 64 & 0,11 & 0,05 \\
9 & & 128 & 0,18 & 0,09 \\
10 & & 256 & 0,18 & 0,08 \\
11 & 200 & 1 & 0,14 & 0,07 \\
\hline
\end{tabular}




\begin{tabular}{ccccc}
\hline No. & $\begin{array}{c}\text { Jarak } \\
\text { (meter) }\end{array}$ & $\begin{array}{c}\text { Besar } \\
\text { Data (byte) }\end{array}$ & $\begin{array}{c}\text { Avg "a" } \\
\text { (kbps) }\end{array}$ & $\begin{array}{c}\text { Avg "b" } \\
\text { (kbps) }\end{array}$ \\
\hline 12 & & 32 & 0,28 & 0,14 \\
13 & & 64 & 0,23 & 0,11 \\
14 & & 128 & 0,28 & 0,14 \\
15 & & 256 & 0,3 & 0,15 \\
16 & & 1 & 0,2 & 0,1 \\
17 & & 32 & 0,27 & 0,14 \\
18 & 300 & 64 & 0,15 & 0,07 \\
19 & & 128 & 0,31 & 0,15 \\
20 & & 256 & 0,35 & 0,17 \\
\hline
\end{tabular}

Pada Tabel 4. dan Tabel 5. menunjukkan bahwa seluruh pengujian dapat diberikan justifikasi cukup baik karena masing dibawah $1 \mathrm{kbs}$ untuk tiap data yang dikirimkan. Tiap pengujian dilakukan sebanyak 20 kali dan diberikan rata-rata pada tabel tersebut.

Tabel 5. Hasil Pengujian Throughput ke-2

\begin{tabular}{|c|c|c|c|c|c|c|}
\hline No. &  & 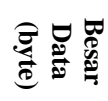 & $\begin{array}{c}\text { Min } \\
\text { "c" } \\
\text { (kbps) }\end{array}$ & $\begin{array}{c}\text { Min } \\
\text { "d" } \\
\text { (kbps) }\end{array}$ & $\begin{array}{c}\text { Max } \\
\text { "e" } \\
\text { (kbps) }\end{array}$ & $\begin{array}{c}\text { Max } \\
\text { "f" } \\
\text { (kbps) }\end{array}$ \\
\hline 1 & & 1 & 0,01 & 0,01 & 0,01 & 0,01 \\
\hline 2 & & 32 & 0,01 & 0,01 & 0,01 & 0,01 \\
\hline 3 & 10 & 64 & 0,01 & 0,01 & 0,01 & 0,01 \\
\hline 4 & & 128 & 0,01 & 0,01 & 0,01 & 0,01 \\
\hline 5 & & 256 & 0,01 & 0,01 & 0,01 & 0,01 \\
\hline 6 & & 1 & 0,06 & 0,03 & 0,06 & 0,03 \\
\hline 7 & & 32 & 0,06 & 0,08 & 0,06 & 0,09 \\
\hline 8 & 100 & 64 & 0,11 & 0,05 & 0,12 & 0,05 \\
\hline 9 & & 128 & 0,18 & 0,09 & 0,18 & 0,09 \\
\hline 10 & & 256 & 0,17 & 0,07 & 0,19 & 0,09 \\
\hline 11 & & 1 & 0,14 & 0,07 & 0,15 & 0,07 \\
\hline 12 & & 32 & 0,28 & 0,14 & 0,28 & 0,15 \\
\hline 13 & 200 & 64 & 0,23 & 0,11 & 0,23 & 0,11 \\
\hline 14 & & 128 & 0,28 & 0,13 & 0,29 & 0,15 \\
\hline 15 & & 256 & 0,3 & 0,15 & 0,3 & 0,17 \\
\hline 16 & & 1 & 0,2 & 0,1 & 0,21 & 0,1 \\
\hline 17 & & 32 & 0,27 & 0,14 & 0,28 & 0,15 \\
\hline 18 & 300 & 64 & 0,15 & 0,07 & 0,17 & 0,08 \\
\hline 19 & & 128 & 0,3 & 0,15 & 0,33 & 0,15 \\
\hline 20 & & 256 & 0,35 & 0,17 & 0,35 & 0,17 \\
\hline
\end{tabular}

Pengujian throughput ini memberikan anomali yang cukup menarik sesuai pada Gambar 6. Pada gambar tersebut menunjukkan pengujian nomor 1-5 dengan jarak 10 meter dan besar data 1 hingga 256 bytes, bahwa throughput yang didapatkan cukup stabil.

Setelah itu pengujian nomor 6 hingga 20 menunjukkan rata-rata hasil yang cukup fluktuatif sehingga waktu yang dipergunakan tidak bisa ditebak. Gambar 6. dapat disimpulkan bahwa jarak tidak menentukan throughput yang didapatkan, namun besar data mempengaruhi kenaikan throughput. Meskipun kenaikan tidak signifikan, tiap baris data pada gambar tersebut terlihat selisih kenaikannya.

\subsection{Pengujian RSSI}

Pengujian selanjutnya, ke-3 adalah melakukan pengujian RSSI. Pengujian ini dilakukan untuk melakukan analisis antara hubungan daya terima sinyal terhadap jarak dan besar data. Tiap komponen pengujian sesuai kriteria pengujian sebelumnya.

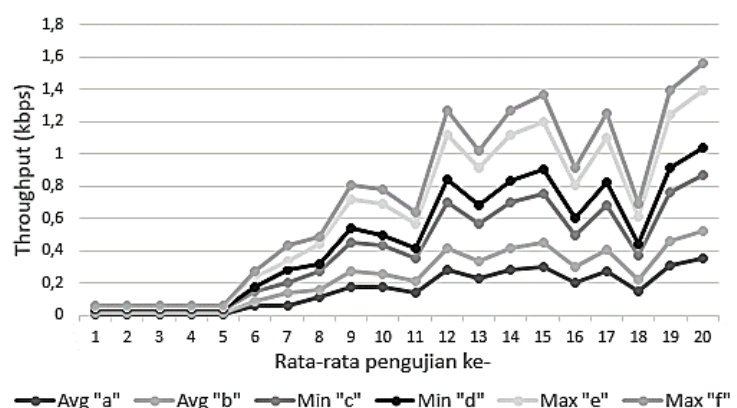

Gambar 6. Rekapitulasi Pengujian Throughput

Tabel 6. Hasil Pengujian RSSI

\begin{tabular}{|c|c|c|c|c|c|}
\hline No. & $\begin{array}{c}\text { Jarak } \\
\text { (meter) }\end{array}$ & $\begin{array}{c}\text { Besar } \\
\text { Data } \\
\text { (byte) }\end{array}$ & $\begin{array}{l}\text { Avg "a } \\
\text { dan b" } \\
(\mathrm{dBm})\end{array}$ & $\begin{array}{l}\text { Avg "b } \\
\text { dan c" } \\
(\mathrm{dBm})\end{array}$ & $\begin{array}{l}\text { Min "c } \\
\text { dan d" } \\
(\mathrm{dBm})\end{array}$ \\
\hline 1 & & 1 & -69 & -71 & -60 \\
\hline 2 & & 32 & -67 & -75 & -65 \\
\hline 3 & 10 & 64 & -63 & -70 & -60 \\
\hline 4 & & 128 & $-66,33$ & -91 & -60 \\
\hline 5 & & 256 & $-70,83$ & -72 & -70 \\
\hline 6 & & 1 & -93 & -95 & -90 \\
\hline 7 & & 32 & -85 & -85 & -85 \\
\hline 8 & 100 & 64 & $-81,33$ & -82 & -80 \\
\hline 9 & & 128 & $-84,16$ & -85 & -84 \\
\hline 10 & & 256 & $-82,16$ & -83 & -80 \\
\hline 11 & & 1 & $-102,16$ & -105 & -90 \\
\hline 12 & & 32 & $-99,16$ & -102 & -93 \\
\hline 13 & 200 & 64 & -91 & -92 & -90 \\
\hline 14 & & 128 & -91 & -92 & -90 \\
\hline 15 & & 256 & $-90,83$ & -91 & -90 \\
\hline 16 & & 1 & $-99,66$ & -103 & -95 \\
\hline 17 & & 32 & -91 & -91 & -91 \\
\hline 18 & 300 & 64 & $-95,33$ & -96 & -95 \\
\hline 19 & & 128 & $-93,83$ & -95 & -93 \\
\hline 20 & & 256 & $-96,66$ & -100 & -96 \\
\hline
\end{tabular}

Pada Tabel 6. menunjukkan bahwa daya terima yang dimiliki oleh LoRa cukup baik. Rentang ratarata yang didapatkan adalah mulai dari 69 hingga 106 dbm. Tabel 6. direpresentasikan pada Gambar 7. menunjukkan bahwa untuk tiap pengujian memiliki rata-rata RSSI yang cukup baik. Jarak dan besar data tidak terlalu berpengaruh terhadap kemampuan RSSI yang dimiliki oleh LoRa.

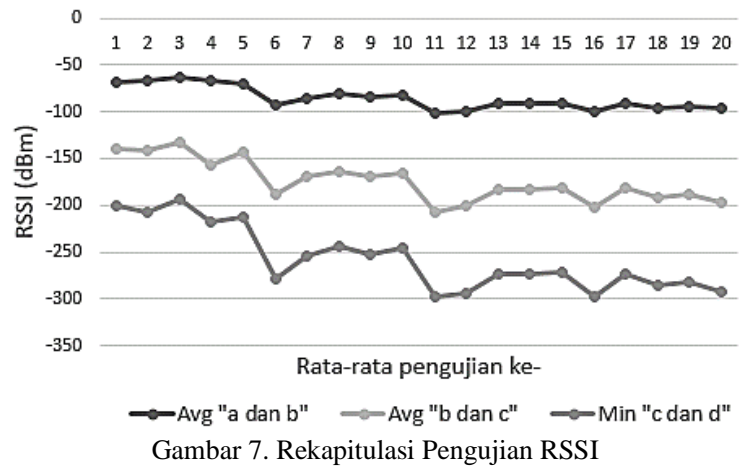

\subsection{Pengujian SNR}

Pengujian terakhir yang dilakukan adalah pengujian SNR. Pada pengujian ke-4 ini dilakukan 
untuk menentukan kualitas sinyal yang dimiliki terhadap besar data dan jarak. Skema pengujian mirip seperti skema yang dilakukan sebelumnya.

\begin{tabular}{cccccc}
\multicolumn{5}{c}{ Tabel 7. Hasil Pengujian SNR } \\
\hline No. & $\begin{array}{c}\text { Jarak } \\
\text { (meter) }\end{array}$ & $\begin{array}{c}\text { Besar } \\
\text { Data } \\
\text { (byte) }\end{array}$ & $\begin{array}{c}\text { Avg "a } \\
\text { dan b" } \\
\text { (dB) }\end{array}$ & $\begin{array}{c}\text { Avg "b } \\
\text { dan c" } \\
\text { (dB) }\end{array}$ & $\begin{array}{c}\text { Min "c } \\
\text { dan d" } \\
\text { (dB) }\end{array}$ \\
\hline 1 & & 1 & 16,29 & 16,25 & 16,5 \\
2 & & 32 & 16,54 & 16,25 & 17,5 \\
3 & \multirow{2}{*}{10} & 64 & 17,33 & 17,25 & 17,5 \\
4 & & 128 & 17,36 & 16,5 & 17,7 \\
5 & & 256 & 16,62 & 16,25 & 17,75 \\
6 & & 1 & 16,37 & 16,25 & 16,5 \\
7 & & 32 & 17,08 & 16,25 & 17,25 \\
8 & \multirow{2}{*}{100} & 64 & 17,25 & 16,25 & 17,5 \\
9 & & 128 & 11,29 & $-16,5$ & 17,5 \\
10 & & 256 & 17,37 & 17,25 & 17,5 \\
11 & & 1 & 17,25 & 17,25 & 17,25 \\
12 & & 32 & 17,2 & 16,5 & 17,75 \\
13 & \multirow{2}{*}{200} & 64 & 17,33 & 17 & 17,5 \\
14 & & 128 & 17 & 16,5 & 17,5 \\
15 & & 256 & 16,58 & 16,25 & 16,75 \\
16 & & 1 & 16,41 & 16,25 & 16,75 \\
17 & & 32 & 17,16 & 16,75 & 17,5 \\
18 & \multirow{2}{*}{300} & 64 & 17,37 & 17,25 & 17,5 \\
19 & & 128 & 17,25 & 17,25 & 17,25 \\
20 & & 256 & 17,5 & 17,5 & 17,5 \\
\hline & & & & &
\end{tabular}

Pada Tabel 7. menunjukkan rata-rata dari masing-masing a, b dst dihitung dari 20 kali pengujian. Hasil pengujian SNR yang didapatkan dari sistem yang disajikan adalah rata-rata dari 40 data. Rata-rata rentang yang dimiliki sangat stabil yaitu antara $16.29 \mathrm{db}$ hingga $17.5 \mathrm{db}$.

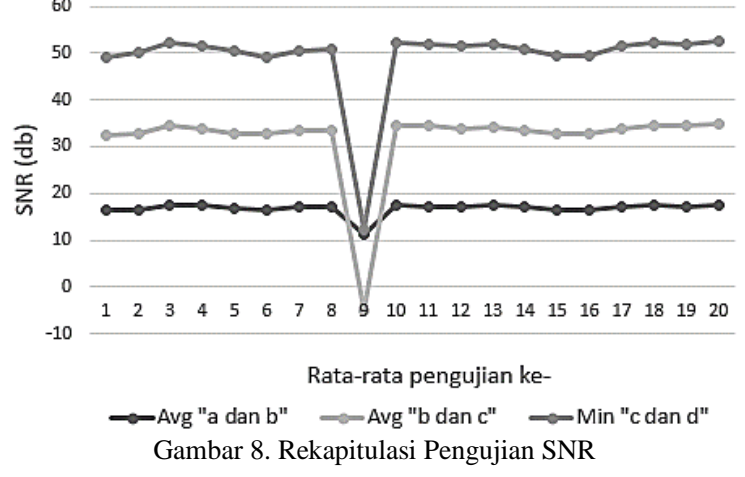

Seluruh data tersebut pada Tabel 7. disajikan pada Gambar 8. menunjukkan anomali yang menarik. Seluruh rentang rata-rata pengujian terhadap jarak tidak berpengaruh terhadap SNR, namun besar data memiliki pengaruh sehingga SNR lebih besar. Pada pengujian ke-9 memiliki rata-rata dibawah dari rata-rata yang lain, penyebab hal ini tidak diketahui, dianggap sebagai data yang memiliki noise paling rendah.

\section{PENUTUP}

Berdasarkan penelitian yang dilakukan, dari proses kajian latar belakang, perancangan hingga hasil dan pembahasan dapat diberikan kesimpulan sebagai berikut. Implementasi WSN dengan LoRa untuk Edge Computing dapat diimplementasikan dengan menggunakan perangkat arduino uno dengan modul komunikasi LoRa SX1287. Perangkat tersebut dipergunakan sebagai sebuah node, baik end node maupun master node. Dimana konsep Edge Computing adalah pengolahan data dilakukan oleh end node, sehingga master node tidak melakukan komputasi terhadap data yang dikirimkan untuk pengambilan keputusan.

Proses analisis kinerja dari penelitian ini melakukan analisis kinerja dari LoRa SX1278 terkait studi kelayakan untuk kehandalan dari LoRa untuk diimplementasikan. Pengujian dilakukan antara lain menguji tentang delay, throughput, RSSI dan SNR. Masing-masing pengujian memiliki anomali yang menarik, namun dapat disimpulkan terkait jarak yang dapat diimplementasikan hingga 300 meter. Pada jarak 300 meter, tampak tidak ada masalah untuk pengujian throughput, RSSI dan SNR. Namun besar data 256 bytes memiliki delay yang kurang baik pada jarak 300 meter.

Sehingga dapat disimpulkan secara keseluruhan terhadap besar dan data untuk delay dan throughput secara keseluruhan fluktuatif besarnya. Namun pada RSSI dan SNR jarak tidak terlalu berpengaruh, namun besar data sedikit berpengaruh. Karena spesifikasi perangkat keras yang cukup minimum, sistem ini dapat disebut juga low cost system karena tidak membutuhkan banyak sumber daya untuk implementasi. Secara keseluruhan pengujian dapat dikatakan cukup baik dan layak untuk diimplementasikan atau dikembangkan lebih lanjut.

Saran untuk penelitian selanjutnya adalah untuk pengembangan sistem ini karena penelitian ini masih jauh dari kelayakan WSN. Penelitian dapat dikembangkan misalkan melakukan kajian terhadap topologi, konfigurasi, komputasi, lokalisasi, proses routing hingga proses low power. Sehingga didapatkan sebuah kajian yang sangat baik terhadap implementasi WSN menggunakan LoRa.

Serta, saran selanjutnya adalah kajian implementasi Edge Computing menggunakan algoritma cerdas yang dapat diimplementasikan pada tiap-tiap end node. Sehingga dapat diukur kemampuan end node untuk melakukan / performa pemrosesan algoritma cerdas pada masing-masing node, karena node tersebut memiliki sumber daya (memori, prosesor, input/output) yang sangat terbatas.

\section{DAFTAR PUSTAKA}

ADIONO, T., PUTRA, R. V. W., FATHANY, M. Y. \& ADIJARTO, W., 2015. Desain Sistem Rumah Cerdas berbasis Topologi Mesh dan Protokol Wireless Sensor Network yang Efisien. INKOM - Jurnal Informatika, Sistem Kendali dan Komputer, 9(2), pp. 6572.

ADIONO, T., PUTRA, R. V. W., FATHANY, M. Y. \& ADIJARTO, W., 2015. Desain Sistem Rumah Cerdas berbasis Topologi Mesh dan 
Protokol Wireless Sensor Network yang Efisien. INKOM - Jurnal Informatika, Sistem Kendali dan Komputer, 9(2), pp. 6572.

AROEBOESMAN, F. N., ICHSAN, M. H. H. \& PRIMANANDA, R., 2018. Analisis Kinerja LoRa SX1278 Menggunakan Topologi Star Berdasarkan Jarak dan Besar Data Pada WSN. Jurnal Pengembangan Teknologi Informasi dan Ilmu Komputer, 3(4), pp. 3860-3865.

ASTUTI, L. D. \& WIBISONO, W., 2017. Peningkatan Network Lifetime Pada Wireless Sensor Network Menggunakan Clustered Shortest Geopath Routing (CSGP) Protocol. Jurnal Teknologi Informasi dan Ilmu Komputer (JTIIK), 4(3), pp. 148153.

BHAWIYUGA, A. \& YAHYA, W., 2018. Sistem Monitoring Kualitas Air Kolam Budidaya Menggunakan Jaringan Sensor Nirkabel Berbasis Protokol LoRa. Jurnal Teknologi Informasi dan Ilmu Komputer (JTIIK), 6(1), pp. 99-106.

BOTERO-VALENCIA, J., CASTANOLONDONO, L., MARQUEZ-VILORIA, D. \& RICO-GARCIA, M., 2019. Data Reduction in a Low-Cost Environmental Monitoring System Based on LoRa for WSN. IEEE Internet of Things Journal, 6(2), pp. 3024-3030.

CAO, L., CAI, Y. \& YUE, Y., 2019. Swarm Intelligence-Based Performance Optimization for Mobile Wireless Sensor Networks: Survey, Challenges, and Future Directions. IEEE Access, 7(1), pp. 161524161553.

CHAO, F. et al., 2018. A Mine WSN Low Consumption Acquisition Method Based on Neural Network. Beijing, China, 2018 14th IEEE International Conference on Signal Processing (ICSP).

COSTA, D. G., 2020. Visual Sensors Hardware Platforms: A Review. IEEE Sensors Journal, 20(8), pp. 4025-4033.

FAUZI, F. A., SUMARYO, S. \& MURTI, M. A., 2018. Desain Dan Implementasi Wireless Sensor Network Pada Sistem Monitoring Kebakaran Hutan Berbasis Internet Of Things. e-Proceeding of Engineering, 5(3), pp. 3869-3878.

ICHSAN, M. H. H., KURNIAWAN, W., SETYAWAN, G. E. \& Sandy, I. A. K., 2019. WSN performance based on node placement by genetic algorithm at smart home environment. Telkomnika, 2(1), pp. 299-306.

ICHSAN, M. H. H., KURNIAWAN, W. \& WULANDARI, A. T., 2019. Fuzzy Logic for Flood Detection System in an
Embedded System. Lombok, Indonesia, 2019 International Conference on Sustainable Information Engineering and Technology (SIET).

RAHARJO, A. R. H., USMAN, U. K. \& JAYADI, Y. T., 2019. Analisis Dan Solusi Dampak Interferensi Dari Sinyal Lora Pada Komunikasi Seluler Band 8 Dan Usulan Untuk Penggelaran Jaringan Lora Di Indonesia. e-Proceeding of Engineering, 6(2), pp. 3208-3214.

SABOR, N., SASAKI, S., ABO-ZAHHAD, M. \& AHMED, S. M., 2017. A Comprehensive Survey on Hierarchical-Based Routing Protocols for Mobile Wireless Sensor Networks: Review, Taxonomy, and Future Directions. Hindawi, Wireless Communications and Mobile Computing, 2017(1), pp. 1-23.

SILVA, W. S. d. et al., 2017. A multilayer link quality estimator for reliable machine-tomachine communication. Montreal, QC, 2017 IEEE 28th Annual International Symposium on Personal, Indoor, and Mobile Radio Communications (PIMRC).

SUJANA, A., 2018. Aplikasi Monitoring Data Wireless Sensor Network Untuk Deteksi Dini Potensi Kebakaran Berbasis Android. Jurnal Isu Teknologi, 13(2), pp. 83-99.

TEIXEIRA, E., PEDREIRAS, P. \& MOTA, A., 2019. Low Power WSN Protocol for Smart Green Homes. Zaragoza, Spain, 2019 24th IEEE International Conference on Emerging Technologies and Factory Automation (ETFA).

Y., W. et al., t.thn. A Rapid Response Approach Applying Edge Computing for Distributed Warehouses in WSN. Singapore, Springer.

YAN, J., ZHOU, M. \& DING, Z., 2016. Recent Advances in Energy-Efficient Routing Protocols for Wireless Sensor Networks: A Review. IEEE Access, 4(1), pp. 5673-5686.

ZHOU, Z. et al., 2019. Edge Intelligence: Paving the Last Mile of Artificial Intelligence With Edge Computing. Proceedings of the IEEE, 107(8), pp. 1738-1762. 